\title{
APLIKASI MOBILE-CUSTOMER RELATIONSHIP MANAGEMENT UNTUK SMALL AND MEDIUM SIZE ENTERPRISES (SMES)
}

\author{
Utaminingsih Linarti \\ Program Studi Teknik Industri \\ Fakultas Teknologi Industri \\ Universitas Ahmad Dahlan Yogyakarta \\ e-mail : utaminingsih.linarti@ie.uad.ac.id
}

\begin{abstract}
The key factor of enterprise in order to still growth and developed is customer. The customer will give the value to the enterprise in the form of profit. Therefore, enterprises must be able to establish an sustainable relationship to customer. Since 1990 began to develop what is called Customer Relationship Management (CRM). CRM implements between the development of information technology and customer-centric views. The development of technology and the human need's to move quickly, CRM evolved into a mobile CRM. The Internet make mobileCRM easily used to all of enterprise, especially small and medium size enterprise. This article is aim to explain the role and the applicability of mobile CRM to business level conditions of small and medium size enterprises (SMEs). The presence of mobile phone operating system that is flexible (android system), the internet cost of affordable and the social media applications as analogy of user interface in making mobile CRM application. CRM mobile application can be downloaded or installed through the app store with ease. It encourages mobile-CRM benefit's rather than as a function of customer data collection but became a window for customer information. In addition, the database can be analysis and relate to customer activity. Mobile CRM applications can take advantage of cross selling methods.
\end{abstract}

Keywords : Customer Relationship Management, mobile-CRM, SMEs

Abstrak

Pelanggan merupakan faktor kunci untuk menjaga enterprise agar tetap tumbuh dan berkembang. Pelanggan akan memberikan 'value' atas apa yang diperoleh kepada enterprise berupa profit. Oleh karenanya, enterprise harus mampu menjalin hubungan yang berkelanjutan kepada pelanggan. Sejak tahun 1990 mulai berkembang apa yang dinamakan Customer Relationship Management (CRM). CRM mengimplementasikan antara perkembangan teknologi informasi dan pandangan customer-centric. Perkembangan teknologi dan kebutuhan manusia yang bergerak cepat, CRM berkembang menjadi mobile-CRM. Internet memudahkan mobileCRM digunakan untuk semua skala perusahaan, apalagi small and medium size enterprise. Tujuan artikel ini adalah menjelaskan peran mobile-CRM dan kemamputerapan mobile-CRM untuk kondisi level bisnis small and medium size enterprises (SMEs ). Kehadiran telepon seluler bersistem operasi yang fleksibel (sistem android), biaya internet yang terjangkau dan aplikasi sosial media sebagai analogi user interface dalam membuat aplikasi mobile-CRM. Aplikasi mobile-CRM dapat diunduh atau dipasang melalui aplikasi store dengan mudah. Hal tersebut mendorong kemanfaatan mobile-CRM bukan sebagai fungsi pengumpul data pelanggan melainkan menjadi jendela informasi untuk pelanggan. Selain itu, dapat dilakukan analisis terkait database dan aktivitas pelanggan. Aplikasi mobile-CRM dapat memanfaatkan metode cross selling.

Kata Kunci : Customer Relationship Management, mobile-CRM, SMEs

\section{PENDAHULUAN}

Pelanggan merupakan faktor kunci untuk menjaga sebuah enterprise agar tetap tumbuh dan berkembang. Seluruh aktivitas produksi yang dilakukan oleh enterprise akan berakhir ke tangan pelanggan. Pelanggan akan memberikan value atas apa yang diperoleh yang berupa profit bagi enterprise. Kale (2004) dalam Lancioni, et al. (2003) menyatakan "developing and maintaining customer relathionship is vital for competitive advantage". Enterprise harus menjalin hubungan terhadap pelanggan (customer relationship) dengan baik. Enterprise harus mampu 
menjaga pelanggan agar tetap "loyal" -tidak ingin berpindah- dan juga harus mampu menjaring pelanggan baru untuk lebih mengembangkan bisnis enterprise. Adanya orientasi bahwa pelanggan sebagai tujuan untuk memperoleh shareholder value enterprise akan merubah ekosistem bisnis, yang pada awalnya adalah mass production kemudian customer driven menjadi customer-centric (Greenberg, 2004, p.11). Pada ekosistem bisnis mass production, penjual adalah raja. Selama ini enterprise lebih berfokus pada proses efisiensi internal. Pada ekosistem bisnis customer driven, enterprise mulai berfokus pada pelanggan, sehingga bukan hanya efisiensi proses dalam enterprise tetapi juga efektivitas market. Pelanggan mulai memiliki kekuatan untuk menentukan apa yang mereka butuhkan karena mereka memiliki banyak alternatif pilihan. Adanya choice dari pelanggan akan mengakibatkan berkembang pula tingkat persaingan (competitiveness) antar enterprise. Sedangkan ekosistem bisnis customercentric, pelanggan adalah pusat segalanya. Enterprise mulai berfokus pada segmented service. Apapun yang dibutuhkan oleh pelanggan akan disediakan oleh enterprise. Enterprise mulai menggunakan strategi bisnis baru dalam ekosistem bisnis ini.

\subsection{Customer-Centric View}

Pelanggan sebagai value-driven bagi enterprise. Saat ini, pelanggan lebih cenderung memperhatikan beberapa hal detail terkait apa yang mereka butuhkan. Pelanggan selalu menginginkan personalisasi atas produk yang sesuai dengan kebutuhan mereka dan menginginkan pelayanan yang super, mulai pengiriman produk, kebutuhan produk hingga pelayanan after sales (get one for all need). Pelanggan akan mencari value terbaik ketika mereka mengambil keputusan untuk membelanjakan sesuatu. Bukan berarti harga akan menjadi satu-satunya faktor penentu. Mereka tidak akan segan untuk mengeluarkan uang yang besar untuk membeli sesuatu, asalkan sesuai dengan value yang mereka harapkan. Value tersebut akan sangat penting bagi enterprise.

Adanya value, memberikan keleluasaan kepada pelanggan untuk melakukan banyak pilihan. Sehingga hal ini akan mendorong tingkat kompetisi antar enterprise. Mau tidak mau, enterprise harus melakukan berbagai cara untuk tetap menjaga pelanggan mereka. Bahkan berupaya untuk menjaring lebih banyak lagi pelanggan baru. Sehingga dalam kondisi ini yang dibutuhkan oleh pelanggan adalah relationship. Pelanggan ingin dianggap sebagai bagian proses dari enterprise bukan hanya sebagai objek akhir enterprise. Oleh karena itu muncul paradigma baru yaitu Costumer Centric. Costumer Centric lebih menekankan pada relationship customer dengan pola hubungan kolaborasi antara enterprise dengan pelanggan.

Fokus Consumer Centric bukan hanya sebagai visi enterprise tetapi bagaimana sebuah perusahaan menjadi sebuah organisasi costumer centric. Enterprise dapat mewujudkan organisasi yang costumer centric dengan melakukan reenginering strategic plan dan measurement to ensure costumer focus. Kemudian terakhir adalah mencari mekanisme agar fungsi-fungsi pemasaran (marketing), penjualan (sales) dan pelayanan (service) dalam enterprise bertemu dalam bentuk real-time. Sistem pemenuhan produk dan layanan oleh enterprise tersikronisasi dengan baik sehingga dapat memperluas nilai kepada pelanggan. Pandangan costumer centric merubah enterprise lebih memfokuskan pada product design.

\subsection{Perkembangan Internet Business Technology}

Internet Business Technology atau e-Business merupakan penerapan Teknologi Informasi dan Komunikasi (TIK) pada suatu bisnis. Ide ini pertama kali diterapkan oleh IBM pada tahun 1996. Penerapan e-Business memungkinkan kegiatan eksternal untuk terintegrasi layaknya bekerja dalam satu ruangan. Selain itu, e-Business memungkinkan hubungan yang lebih terorganisasi dengan individu, kelompok, maupun entitas bisnis lain.

Pada awalnya banyak yang berfikiran bahwa e-Business adalah e-Marketing atau eCommerce yaitu cara baru untuk memasarkan produk atau cara baru untuk berjualan. Hal ini sempat memicu kejadian yang diberi nama "dot com bubble" yaitu spekulasi yang berlebihan dari para pengusaha hingga melakukan investasi yang besar untuk kegiatan pembangunan situs jual beli dan situs pemasaran. Pada akhirnya, hal-hal ini tidak dapat meningkatkan penjualan sehingga konsep ini dianggap tidak berhasil.

e-Commerce merupakan salah satu komponen dalam e-Business. Secara sederhana, eBusiness dapat dibagi dalam tiga kategori yaitu: internal business system, enterprise communication and collaboration, dan electronic commerce. Dengan demikian, apabila dipandang dari sudut pandang rantai nilai dari enterprise, e-Business dapat memberikan andil 
di sepanjang proses. Adanya internet business technology memberikan dampak signifikan terhadap iklim bisnis.

\subsection{Pola Hubungan Kolaborasi}

Pola hubungan yang terdapat dalam lingkungan antar enterprise memiliki beberapa istilah yang umum digambarkan, yaitu koordinasi, kooperasi dan kolaborasi. Ketiganya memiliki definisi konsep yang berbeda. Menurut Spekman et al (2003) dalam Singh \& Power (2009) menyatakan bahwa koordinasi, kooperasi dan kolaborasi memiliki perbedaan pada tingkat kepercayaan dan komitmen. Spekman et al (2003) menjelaskan urutan level terendah adalah koordinasi, kemudian kooperasi dan terakhir adalah kolaborasi. Definisi kolaborasi menurut Foster et al (2005) dalam Singh \& Power (2009) adalah bermacam-macam entitas yang saling berkerja bersama serta berbagi proses, teknologi dan data untuk memaksimalkan nilai untuk keseluruhan entitas dan pelanggan yang akan mereka layani.

Sejak awal tahun 1990 mulai berkembanglah apa yang dinamakan Customer Relationship Management (CRM). Customer Relationship Management (CRM) menjembatani antara perkembangan teknologi yang pesat dan perubahan ekosistem bisnis enterprise. Indonesia sebagian besar termasuk small and medium size enterprise (SMEs). Small and medium size enterprise (SMEs) juga dapat mengambil manfaat dari peranan CRM untuk mengembangkan bisnis.

Artikel ini memiliki 2 tujuan utama, yaitu menjelaskan peran mobile-CRM dalam mendukung grand design CRM dan kemamputerapan mobile-CRM untuk kondisi level bisnis small and medium size enterprises (SMEs).

\section{Studi Literatur}

Sebuah strategi hubungan pelanggan harus membahas pendefinisian segmen pasar dengan baik, masing-masing dievaluasi dari segi potensi keuntungan (profitabilitas) saat ini dan masa depan (Roberts, et al., 2005). Menurut Kutner and Cripps (1997) dalam Knox \& Ryals (2001), terdapat empat hubungan pelanggan (customer relationship) dalam CRM yaitu pelanggan sebagai aset penting, pelanggan memiliki variasi keuntungan, variasi pelanggan berdasarkan kebutuhan, preferensi, memahami nilai portofolio pelanggan.

Keputusan pemilihan strategi yang didapat selanjutnya mencari solusi teknologi apa yang cocok dalam mengembangkan hubungan pelanggan yang diinginkan. Seperti Thakur et al (2006) dalam Frow \& Payne (2009) mengamati: "Ada banyak komponen teknologi dalam CRM, tetapi berpikir tentang CRM dalam hal teknologi terutama tanpa strategi akan menjadi suatu kesalahan. Hal ini lebih berguna untuk mengkarakterisasi CRM sebagai sebuah proses kompleks yang mengintegrasikan informasi tentang pelanggan, penjualan, kesadaran pelanggan, dan tren pasar.

Beberapa penulis telah membuat framework strategy dari CRM agar mudah diaplikasikan dalam enterprise. Frow dan Payne (2009) menunjukan framework mengenai pemilihan strategi terhadap hubungan enterprise dengan pelanggan. Framework ini terbagi menjadi 4 kuadran yang menggambarkan strategi matriks hubungan antara enterprise dengan pelanggan. Dalam matrik strategi tersebut, sumbu horisontal menyatakan degree of customer individualization sedangkan sumbu vertikal menyatakan completeness of customer information. Degree of customer individualization menjelaskan mengenai level hubungan pelayanan enterprise terhadap pelanggan berdasarkan informasi yang didapat. Sedangkan completeness of customer information menjelaskan mengenai dimensi ukuran informasi, menetukan beberapa banyak informasi yang didapat dari pelanggan dan level pengalaman dari analisis informasi yang sudah didapatkan tersebut.

Sistem komunikasi melalui media mobile antara enterprise dengan pelanggan tidak sama dengan media komunikasi yang lain. Perbedaan berkomunikasi melalui media mobile dapat dilihat dari karakteristik media mobile, fase komunikasi dan ragam komunikasi. Media mobile, memiliki kemampuan unik yang melebihi media lain, yaitu layanan messanging (SMS dan MMS). Layanan ini memberikan kemudahan pelanggan untuk berkomunikasi dengan enterprise, one to one marketing. Berdasarkan Sinisalo (2011), fase komunikasi dengan media mobile dibedakan menjadi dua yaitu fase inisiasi dan fase perbaikan. Hubungan kedua fase tersebut dapat dilihat pada gambar 1.

Mobile-CRM memiliki perbedaan yang unik dengan media CRM yang lain yaitu komunikasi bersifat personal (personalization), interaktif dan fleksibel. Mobile phone menyediakan semua fitur yang penting untuk mebangun dialog langsung antara enterprise 
dengan pelanggannya. Alahuhta, et al (2005) dalam artikelnya memperkenalkan konsep mobile-CRM sebagai CRM O'Reilly \& Paper (2009)dengan menggunakan mobile terminals seperti mobile phones yang disebut sebagai smart phones dan Personal Digital Assistant. Teknologi yang digunakan adalah teknologi Java. Dari teknologi tersebut maka yang digunakan sebagai bangunan blocks untuk membangun mobilized CRM adalah ketersediaan sistem informasi, mobile service dengan aplikasi yang tersedia dan database pelanggan.

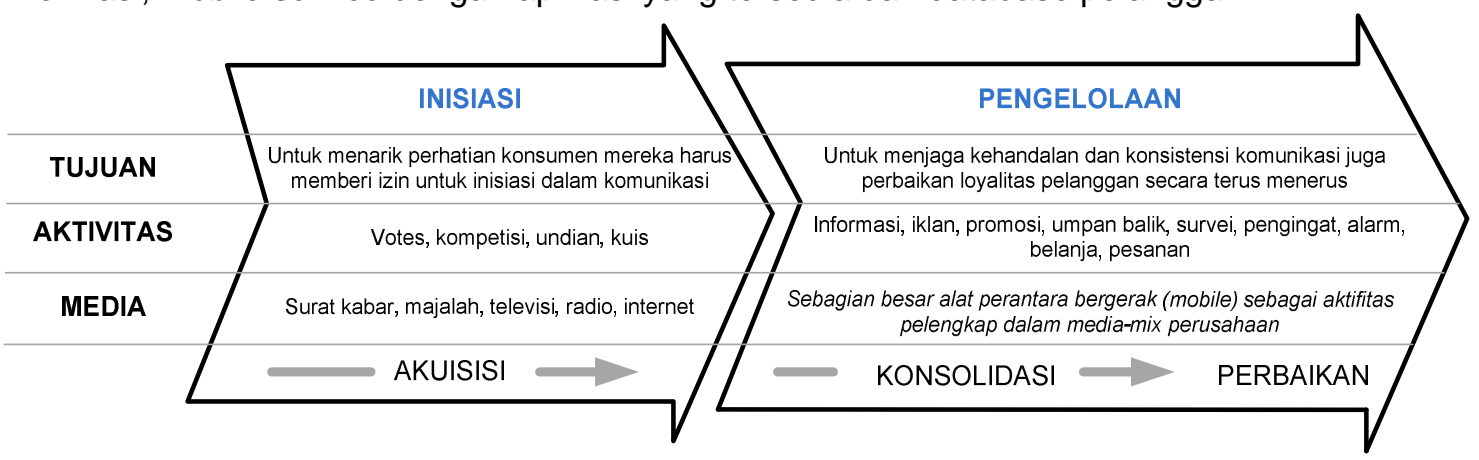

Gambar 1. Fase komunikasi dengan media mobile (Sinisalo, 2011)

Pemanfaatan strategi bisnis CRM selama ini hanya dilihat untuk penggunaan enterprise besar. Padahal, seluruh level bisnis dapat menggunakan strategi ini. Beberapa paper yang telah membahas mengenai pemanfaatan CRM untuk diterapkan untuk SMEs diantaranya Balocco, et al (2009); Harrigan, et al. (2008); Harrigan, et al (2009); Harrigan, et al (2012); Löffler, et al (2011); Ramdani, et al (2009); Zheng (2011). Paper tersebut menjelaskan beberapa hal mengenai penerapan teknologi CRM pada umumnya dan mobile CRM pada khususnya digunakan untuk level bisnis enterprise kecil menengah. Karakteristik kesuksesan atau kegagalan dari penerapan CRM pada enterprise level kecil dan menengah disebabkan antara lain : kepemimpinan, budaya dan manusia; proses bisnis dan integrasi sistem dan data

Dari sisi teknologi jaringan, mobile-CRM dibedakan atas teknologi seluler dan teknologi WiFi. Sarana yang digunakan untuk aplikasi mobile-CRM adalah yang bersifat mudah dipindahkan dan peralatan tersebut mengikuti pengguna aplikasinya. Berikut ini adalah contohcontoh sarana yang umum atau berpotensi menjadi sarana aplikasi.

a. Telepon seluler biasa: Spesifikasi telefon ini berkemampuan 2G. Pemanfaatan m-CRM menggunakan SMS, Interactive Voice Response (IVR), ataupun Unstructured Suplementary Service Data (USSD).

b. Telepon seluler EDGE atau 3G: memiliki kemampuan seperti telepon seluler biasa. Pemanfaatan m-CRM dapat dengan melakukan browsing serta penerimaan maupun pengiriman MMS.

c. Perangkat berkemampuan WiFi saja seperti: PDA, tablet.

d. Telepon seluler dengan kemampu-pasangan applikasi: telepon seluler dengan system operasi Blackberry, Symbian, iOS, Android, Windows Phone.

e. Perangkat pembantu kerja dengan modul seluler atau WiFi seperti pemindai elektronik untuk meteran listrik, printer resi, mesin EDC, printer WiFi, alat navigasi interaktif.

Valsecchi (2007) memberikan contoh aplikasi yang telah diterapkan di Italia, antara lain:

a. Administrasi publik menggunakan SMS untuk memberikan informasi kepada warga mengenai kontrak, layanan publik, berita dan acara setempat.

b. Sebuah organisasi kesehatan umum menyediakan fasilitas booking dan pemberitahuan via SMS dan e-mail.

c. Dinas perhubungan di suatu kota bekerja sama dengan pengelola teknologi dan bank agar pemilik kendaraan dapat membayar parkir via SMS.

d. Bank menyediakan fasilitas informasi kepada pelanggan atas adanya pemasukan uang ke rekening, pembayaran / transfer, serta status saldo. e-Bay Italia menyediakan fasilitas pemberitahuan via SMS bagi pelanggan yang sedang mengikuti lelang.

\section{Metodologi Penelitian}

Model konseptual pengembangan aplikasi mobile-CRM untuk small and medium enterprise size (SMEs) dilakukan dengan melakukan kajian terhadap berbagai jurnal, pendapat para pakar serta sumber lain yang dipandang relevan. Analogi terhadap model konseptual 
aplikasi yang sudah ada sesuai dengan tujuan dan fungsi yang dapat di aplikasikan pada small and medium size enterprise (SMEs) yang ada di Indonesia.

\section{Hasil dan Pembahasan}

Sekitar tahun 2005, masyarakat semakin mudah memperoleh telepon seluler. Sehingga seharusnya small and medium size enterprise (SMEs) mulai melirik untuk memanfaatkan perangkat tersebut untuk menarik pelanggan agar loyal dan sebanyak-banyaknya. Pada masa kini, mobile CRM masih lebih fokus pada pengumpulan data dari pelanggan dan sebagai media pemasaran. Perkembangan implementasi mobile CRM dengan kehadiran telepon seluler bersistem operasi yang mudah (Android) serta biaya internet yang tetap serta terjangkau akan lebih mengembangkan bisnis enterprise kedua level tersebut. Telepon seluler bersistem operasi dapat dengan leluasa dipasangkan dengan aplikasi tambahan.

PT Raya Novatec memberikan layanan m-CRM yang lebih sederhana yaitu menggunakan SMS. Target pelanggannya adalah sekolah dan usaha kecil menengah. Biaya yang dikenakan untuk paket ekonomi berupa deposit $\mathrm{Rp} 400.000$,- yang akan dikembalikan $100 \%$ pada akhir kontrak. Biaya jasa pemakaian sebesar Rp 300.000,- per tahun. Paket ekonomi ini sudah dapat mengakomodasi layanan informasi, registrasi pelanggan, pemesanan, pengaduan, dn sapa pelanggan. Selain paket ekonomi, terdapat paket standar dan lengkap dimana pada paket-paket tersebut terdapat layanan yang lebih lengkap seperti cek harga, promosi, pemasaran, dan customer profiling. Beberapa outlet penjualan elektronik maupun telepon seluler yang ada di Indonesia telah menggunakan mobile-CRM. Mereka memberikan informasi kepada pelanggan yang pernah berkunjung atau berkomunikasi dengan mereka. Memberikan informasi harga produk, layanan dan lain sebagainya hanya melalui SMS.

Beberapa aplikasi mobile-CRM sudah banyak dikembangkan dan telah banyak digunakan, antara lain vinnoCRM, zohoCRM, temanCRM, matiCRM dan lain-lain. Terdapat 3 komponen utama dalam vinnoCRM yaitu, helpdesk, marketing automation, dan sales force automation. Mobile-CRM tidak lagi hanya berfungsi sebagai pengumpulan data dari pelanggan, melainkan juga sebagai jendela informasi untuk pelanggan. Adanya pilihan aplikasi yang ada diatas dapat dengan mudah diunduh dan dipasang, pelanggan dapat memilih informasi apa yang hendak ditampilkan pada ponsel. Aplikasi tersebut dapat berbayar maupun tidak berbayar. Pilihan aplikasi ini juga memanfaatkan metode cross-selling yaitu memberi informasi aplikasi sejenis atau aplikasi lain yang turut serta diunduh ketika pengguna lain mengunduh suatu aplikasi tertentu. Adanya koneksi internet, SMEs dapat mempelajari forum-forum, blog, facebook, twitter maupun instagram untuk memahami trend keinginan pelanggan saat ini. Sosial media yang sudah ada saat ini sangat membantu dan telah banyak digunakan untuk mengembangkan bisnis online.

\subsection{Komponen Sistem mobile-CRM (m-CRM) untuk SMEs}

Perusahaan dengan skala kecil dan menengah dapat menggunakan media sosial untuk mengembangkan bisnisnya. Pada saat ini, media sosial lebih banyak digunakan untuk mempromosikan produk yang akan dijual. Media sosial merupakan aplikasi yang mudah diunduh atau diinstall di ponsel melalui play store, google store atau aplikasi store lainnya. Sosial media yang sudah ada saat ini sangat membantu dan telah banyak digunakan untuk mengembangkan bisnis online. Perusahaan dengan skala kecil dan menengah dapat menggunakan media sosial untuk mengembangkan bisnisnya. Pada saat ini, media sosial lebih banyak digunakan untuk mempromosikan produk yang akan dijual. Media sosial merupakan aplikasi yang mudah diunduh atau diinstall di ponsel melalui play store, google store atau aplikasi layanan konten digital lainnya.

Aplikasi mobile-CRM yang sudah ada dapat dikolaborasikan dengan media sosial lain yang sudah familiar seperti instagram. Media sosial dapat pula dikembangkan dengan memberikan analisis yang ada pada aplikasi mobile-CRM. Sehingga aktivitas antara pengguna yang dalam hal ini dapat sebagai pelanggan atau calon pelanggan dapat teranalisis dengan baik.

Hal ini dapat membantu usaha dengan skala kecil dan menengah untuk mengembangkan bisnis berasal dari analisis tingkah laku pelanggan atau calon pelanggan. Produk-produk yang dijual oleh usaha kecil dan menengah dapat ditawarkan dalam jendela pajang dalam bentuk gambar pada aplikasi (social media). Interaksi antara pemilik dan pelanggan dapat ditambahkan dalam aplikasi tersebut. Analisis terhadap kuantifikasi jumlah pengunjung, jumlah favorit terhadap suatu barang, jumlah pesanan, pembayaran, dan fitur lain 
dapat dimanfaatkan langsung oleh pemilik atau pengelola usaha langsung dengan mengirimkan notifikasi langsung ke ponsel jika aplikasi CRM ini telah dipasang pada ponsel. Komponen sistem dapat mengadopsi mobile-CRM yang dikembangkan oleh alahuhta et al (2005). Konsep bangunan mobile-CRM yang dikembangkan alahuhta et al (2005) dapat dilihat pada gambar 2.

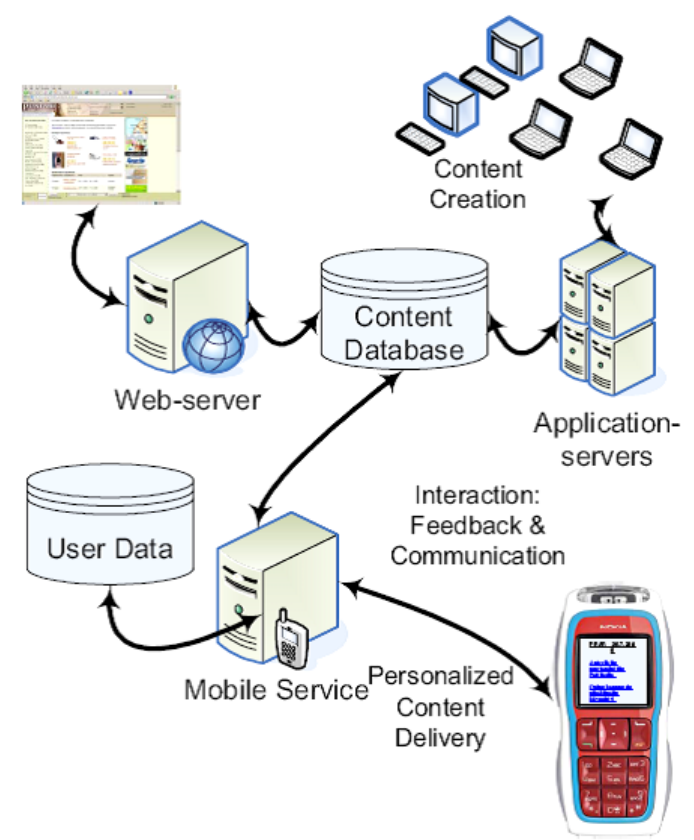

Gambar 2. Konsep bangunan m-CRM Alahuhta et al (2005)

Aplikasi mobile-CRM ini akan berisi data base bidang usaha skala kecil dan menengah, sehingga masing-masing dapat dikelompokkan dan memudahkan pelanggan atau calon pelanggan mencari produk yang akan dibeli. Setiap unit usaha dapat mendaftarkan pada database utama dan akan terhubung pada jendela personal yang berisi aplikasi terkait penjualan, pembelian, feedback dan lain sebagainya. Setiap orang yang memiliki aplikasi ini dapat dengan mudah untuk memberikan informasi kepada penjual dalam hal ini adalah usaha kecil dan menengah terkait produk yang dipajang pada jendela pajang. Setiap aktivitas yang masuk dalam jendela pajang akan di analisis kemudian menjadi notifikasi bagi pengelola usaha. Sehingga dapat setiap saat merespon analisis tersebut.

Konsep mobile-CRM dapat dengan mudah digunakan untuk perkembangan usaha skala kecil dan menengah. Sarana pendukung dapat dengan mudah diperoleh. Sosialisasi kepada calon pelanggan juga dengan cepat dapat dilakukan dengan bantuan media sosial untuk mengunduh aplikasi yang nantinya akan dibuat. Selain untuk masyarakat lokal, aplikasi ini juga dapat berpotensi untuk pengguna masyarakat asing. Sehingga kebutuhan pencapaian global trading dapat dengan mudah di capai. Small and Medium size Enterprise mampu bersaing dengan enterprise-enterprise besar.

\subsection{Keuntungan mobile-CRM SMEs}

Keuntungan dari penggunaan mobile-CRM untuk SMEs adalah sebagai berikut :

a. Personal

Ponsel sebagai perangkat yang dimiliki oleh setiap maka informasi yang disampaikan bersifat pribadi. Sehingga pelanggan dapat dengan mudah memberikan preferensi serta mudah memantau loyalitas pelanggan.

b. Familiar

Penggunaan perangkat pribadi sehingga pelanggan lebih berani untuk menjelajah. Sehingga pelanggan dapat lebih biasa atau akrab memberi penilaian dan mencari apa yang mereka inginkan

c. Interaktif : 
Memungkinkan pelanggan untuk memasukkan informasi, baik sekedar menentukan pilihan maupun informasi baru, dengan demikian pelanggan tidak merasa dijadikan objek.

d. Data mining :

Sifatnya elektronik, data yang diperoleh bisa langsung diorganisasikan dengan baik meskipun data tersebut sangat banyak

e. Customer Intelligence:

Dapat dilakukan analisis yang sederhana sehingga dapat memberikan gambaran mengenai pelanggan misalnya : sifatnya, keinginannya, keluhannya.

f. Manajemen informasi dan distribusi informasi yang lebih mudah, tidak dibutuhkannya medium fisik, maka SMEs dapat menghemat pengadaan kertas dan formulir serta terhindar dari masalah kehabisan stok kertas dan formulir.

g. Lead time informasi

Informasi dapat disebarkan kepada semua entitas yang berkepentingan saat itu juga ketika pelanggan memasukkan informasi ke dalam aplikasi mobile-CRM yang telah dipasang

h. Peningkatan pendapatan

Meningkatkan pendapatan melalui pengurangan biaya misalnya biaya pengadaan medium fisik serta pengurangan biaya penanganan keluhan. Selain pengurangan biaya, juga berkurangnya kecurangan yang terjadi pada rantai penyerahan uang dari pelanggan ke enterprise melalui pegawai maupun pihak ketiga. Peningkatan pendapatan juga terjadi akibat lebih aktifnya interaksi enterprise dengan pelanggannya.

\section{Kesimpulan}

CRM merupakan strategi bisnis dalam mendekatkan enterprise dengan pelanggan. Dipandang sebagai strategi bisnis maka setiap enterprise harus memiliki komitmen sebagai organisasi yang customer centric. Seluruh fokus aktivitas enterprise harus mengarah pada pelanggan. Enterprise tidak boleh memandang CRM sebagai alat yang kemudian di adopsi ke dalam enterprise menggunakan fasilitas IT saja. Enterprise menganggap CRM hanya sebagai sebuah teknologi baru. CRM bukanlah sebuah teknologi. CRM merupakan perspektif strategis dan taktis dalam mengelola pelanggan untuk menghasilkan value lebih bagi perusahaan. Perusahaan memberikan kekuatan lebih baik dari segi kualitas produk dan pelayanan kepada pelanggan kunci mereka. Sehingga dapat dikatakan bahwa CRM merupakan bagian dari sebuah strategi relationship marketing enterprise.

Mobile-CRM memungkinkan SMEs untuk memperlengkapi karyawannya di lini paling depan yaitu para sales dan teknisi servis dengan telepon seluler murah dan biaya operasional yang murah dengan mempergunakan SMS (apalagi adanya service provider dengan gencarnya promo SMS gratis ke sesama operator seluler). Hal tersebut ditunjukkan dengan banyaknya manfaat yang diperoleh dengan adanya penggunaan mobile-CRM.

Informasi yang ada masih dalam bentuk data mentah yang belum diorganisasikan dan belum dapat dianalisis langsung, yaitu dalam bentuk tulisan di forum, twitter, facebook, dan lainlain sehingga membutuhkan usaha yang berlebih dari SMEs serta perlu daya analisis terhadap data yang diperoleh. Sebuah penelitian lanjutan yang dapat dilakukan adalah membuat aplikasi mobile-CRM yang mampu mengakomodasi jendela interface seperti analog sosial media yang terintegrasi dengan sistem analisis data untuk SMEs. Selain itu, juga dapat dilakukan penelitian , bagaimana mengumpulkan dan menganalisis data yang tersebar di forum untuk dapat dimanfaatkan oleh usaha kecil dan menengah?

\section{DAFTAR PUSTAKA}

Alahuhta, P., Helaakoski, H. \& Smirnov, A., 2005. Adoption of Mobile Services in BusinessCase study of Mobile CRM., Proceedings of the 2005 IEEE International Conference on e-Business Engineering (ICEBE'05).

Balocco, R., Mogre, R. \& Toletti, G., 2009. Mobile Internet and SMEs: a Focus on the Adoption. Industrial Management \& Data Systems, 109(2), pp. 245-261.

Frow, P. \& Payne, A., 2009. Customer Relationship Management : a Strategic Perspective. Journal of Business Market Management, 3(1), pp. 7-28

Greenberg, P., 2004. CRM at the Speed of Light. 3rd ed. California: McGraw-Hill

Harrigan, P., Ramsey, E. \& Ibbotson, P., 2008. e-CRM in SMEs: an Exploratory Study in Northern Ireland. Marketing Intelligence \& Planning, 26(4), pp. 385-404. 
Harrigan, P., Ramsey, E. \& Ibbotson, P., 2009. Investigating the e-CRM Activities of Irish SMEs. Journal of Small Business and Enterprise Development, 16(3), pp. 443-465.

Harrigan, P., Ramsey, E. \& Ibbotson, P., 2012. Entrepreneurial Marketing in SMEs: the Key Capabilities of e-CRM. Journal of Research in Marketing and Entrepreneurship, 14(1), pp. 40-64.

Knox, S. \& Ryals, L., 2001. Cross-funcional Issues in the Implementation of Relationship Marketing throuh Customer Relationship Management (CRM). European Management Journal, 19(5), pp. 534-542

Lancioni, R., Schau, H. J. \& Smith, M. F., 2003. Internet Impacts on Supply Chain Management. Industrial Marketing Management, Volume 32, pp. 173-175

Löffler, C., Kröckel, J. \& Hettich, M., 2011. Enabling Mobile Customer Relationship Management for Small and Medium-sized Enterprises. Journal of Computer Information Systems and Industrial Management Applications, Volume 3, pp. 655-662

O'Reilly, K. \& Paper, D., 2009. The Role of Vendor in eCRM Tool Development. Qualitative Market Research: An International Journal, 12(4), pp. 404-427.

Ramdani, B., Kawalek, P. \& Lorenzo, O., 2009. Predicting SMEs' Adoption of Enterprise Systems. Journal of Enterprise Information Management, 22(1), pp. 10-24

Roberts, M., Liu, R. R. \& Hazard, K., 2005. Strategy, Technology and Organizational Alignment: Key Components of CRM Success. Journal of Database Marketing \& Customer Strategy Management, 12(4), pp. 315-326

Singh, P. J. \& Power, D., 2009. The Nature and Effectiveness of Collaboration Between Firms, Their Customers and Suppliers: a Supply Chain Perspective. Supply Chain Management: An International Journal, 14(3), pp. 189-200.

Sinisalo, J., 2011. The Role of the Mobile Medium within Multichannel CRM. International Journal of Electronic Customer Relationship, p. in press

Valsecchi, M., Renga, F. M. \& Rangone, A., 2007. Mobile Customer Relationship Management: an Exploratory Analysis of Italian Applications. Business Process Management Journal, 13(6), pp. 755-770.

Zheng, V., 2011. The Value Proposition of Adopting m-CRM Strategy in UK SMEs. Journal of Systems and, 13(2), pp. 223-245 